\title{
Effect of combine motion on variation of resonance properties in liquid sloshing problems
}

\author{
Konstantinov O. V. ${ }^{1}$, Limarchenko O. S. ${ }^{2}$, Semenovich K. O. ${ }^{3}$ \\ ${ }^{1}$ Institute of Mathematics NAS of Ukraine, \\ Tereshchenkivska street, 3, 01601, Kyiv, Ukraine \\ ${ }^{2}$ Taras Shevchenko National University of Kyiv, \\ 4-E, Academician Glushkov avenue, 01033, Kyiv, Ukraine \\ ${ }^{3}$ Taras Shevchenko National University of Kyiv \\ 4-E, Academician Glushkov avenue, 01033, Kyiv, Ukraine
}

(Received 30 March 2015)

\begin{abstract}
Variation of resonant properties of the system liquid - structure caused by changes of distribution of normal frequencies is under consideration. It was shown that different types of mobility of carrying body (translational or rotational motion with different types of constraints) causes growth of normal frequencies, which correspond to antisymmetric oscillations of a liquid free surface, while the rest of frequencies do not change. General arrangement of normal frequencies, which corresponds to the case of immovable reservoir, is considerably violated. In this case some new types of internal resonances in liquid structure systems are manifested. Two basic problems with redistribution of sequence of normal frequencies were investigated, namely, parametric resonance of movable in translational direction cylindrical reservoir in the Faraday generalized problem and forced motion of liquid in cylindrical reservoir on pendulum with different lengths of suspension. Some general regularities of development of dynamical processes in these systems are discussed.
\end{abstract}

Keywords: nonlinear dynamics of liquid, liquid sloshing, combined motion, redistribution of normal frequencies

2000 MSC: 76B07, 76B99

UDC: 532.595

\section{Introduction}

Recent investigation of nonlinear problems of dynamics of structures with free surfaced liquid showed considerable change of dynamical properties of system behavior in the case of combined motion of the system [1,2]. These investigations showed that even important part of linear properties of such systems changes, because normal frequencies of the system in combined motion and in gives motion of the carrying body are different. Majority of the present investigations are done for reservoirs, which either immovable or perform given motion. Few investigations are performed for systems, when carrying body performs rotational motion. However recent investigations showed $[1,2]$ that namely in the case of rotational motion of the carrying body considerable difference between cases of specified and combined motion of the carrying body occurs.

In the present article we explain main differences in manifestation of dynamical properties between the cases of specified and combined motion of the carrying body. For confirmation of these ideas we consider two examples of combined motions of free surfaced liquid and carrying body, namely, the generalized Faraday problem about parametric resonance of oscillations of liquid free surface on oscillating in vertical direction of cylindrical reservoir, which motion in horizontal direction is not fixed, and angular motion of cylindrical reservoir on pendulum suspension with different lengths.

The main result of analysis of dynamical behavior of these systems make it possible to draw conclusion that in the case of combined motion of the system usual distribution of frequencies, peculiar 
to the case of immovable or movable according to the specified law carrying body, is violated considerable. If we arrange traditionally frequencies in ascending order, both magnitudes of frequencies and arrangement of modes of motion of a liquid free surface are different in the case of specified and combined motions.

\section{General questions of effect of combined character of system motion on distribution of frequencies}

Let us make use of the system of equations for combined motion of free surfaced liquid and movable carrying body [1]. However, we restrict ourselves only by linear system of equations, because now we focus our attention only on resonant properties of the system. So, we write down the linear system of ordinary differential equations relative to amplitude of the first normal mode $a_{1}$, one parameter of translational motion of the reservoir $\varepsilon$ and one parameter $\alpha_{2}$ of rotational motion of the carrying body

$$
\begin{gathered}
\ddot{a}_{1}+\frac{1}{\alpha_{1}^{v}} \ddot{\varepsilon} B_{1}^{1}+\frac{1}{2 \alpha_{1}^{v}} \ddot{\alpha}_{2} E_{11}^{1 *}+\Omega_{1}^{2} a_{r}=0 ; \\
\frac{\rho}{M_{r}+M_{1}} \ddot{a}_{1} B_{1}^{1}+\ddot{\varepsilon}+\frac{\rho}{M_{r}+M_{1}} \ddot{\alpha}_{2} F_{2}^{1}=0 ; \\
\ddot{a}_{i} E_{21}^{1 *}+2 \ddot{\varepsilon} F_{2}^{1}+2 \ddot{\alpha}_{2}\left(\frac{1}{\rho} I_{\text {res }}^{11}+E_{11}^{2}\right)+\frac{2 g}{\rho}\left(M_{r} h_{r}+M_{1} h_{1}\right) \alpha_{2}=0 .
\end{gathered}
$$

Here coefficients $\alpha_{1}^{v}, B_{1}^{1}, E_{11}^{1 *}, F_{2}^{1}, E_{11}^{2}$ are determined from normal modes of oscillations and the Stokes-Zhukovskiy potential [1], $\rho$ is liquid density, $M_{r}$ and $M_{1}$ are masses of reservoir and liquid correspondingly, $I_{\text {res }}^{11}$ is the component of inertial tensor of reservoir, which corresponds to inclination relative to angle $\alpha_{2}, h_{r}$ and $h_{1}$ are displacements of mass centers of reservoir and liquid relative to position of undisturbed free surface of liquid. These equations include only antisymmetric normal mode (with circumferential number $m=1$ ) with amplitude $a_{1}$, because virtual masses $B_{1}^{1}$ and virtual moments of inertia $F_{2}^{1}$ for all normal modes with $m \neq 1$ are vanish. Therefore. there interaction with translational or rotational motion of the reservoir is absent.

If we analyze every equation of the system (1)-(3) separately, we can find three partial frequencies

$$
\begin{gathered}
\omega_{a}^{p}=\Omega_{1}=\sqrt{\frac{\varkappa_{1} g}{R} \tanh \left(\frac{\varkappa_{1} H}{R}\right)}, \quad \omega_{\varepsilon}^{p}=0, \\
\omega_{\alpha}^{p}=\sqrt{\frac{M_{r} h_{r}+M_{1} h_{1}}{I_{\text {res }}^{11}}} .
\end{gathered}
$$

Let us note that it is useful to analyze these results from point of view of the presence of recovering force in free oscillations of uncoupled system. Since gravity is present, liquid tries to pass into equilibrium state. Under the presence of pendulum suspension again gravity promotes returning of the inclined reservoir to equilibrium position. At the same time for translational motion of the reservoir recovering force is absent, therefore, the corresponding partial frequency is zero. This considerably changes situation of translational motion of carrying body and motion of carrying body on pendulum suspension.

We consider two examples of system combined motion. In the first case we study general cases of behavior of the system, when carrying body can perform translational motion. In this case only equations (1) and (2) are sufficient and we can state $\alpha_{=}$. In the second case we consider angular motion of the carrying body on pendulum suspension. Only equations (1) and (3) are necessary, while $\varepsilon=0$. 
Combined motion of the system in translational motion will occurs with two normal frequencies

$$
\omega_{a}^{N}=\frac{\omega_{a}^{p}}{\sqrt{1-\frac{\rho\left(B_{1}^{1}\right)^{2}}{M_{r}+M_{1}}}} ; \quad \omega_{\varepsilon}^{N}=0 .
$$

So, one frequency does not change, however another one, which corresponds to liquid sloshing, increases. This variation of frequencies completely corresponds to theorem about distribution of normal and partial frequencies, which states that normal frequencies should locate outside the segment, which is bounded by partial frequencies [3]. Taking into account that frequency is always nonnegative the frequency $\omega_{\varepsilon}^{N}=0$ cannot decrease. Numerical and qualitative analysis of variation of normal frequency for liquid shows that only for ratio of mass of reservoir to mass of liquid 50 or greater one can neglect changes of frequencies caused by mobility of reservoir in its translation motion. However this ratio of masses is too far from engineering practice, when usually mass of liquid exceeds mass of reservoir $M_{r}<M_{1}$.

At the same time position of other normal frequencies for $m \neq 1$ will not change. So, potential of new internal resonances appear and arrangement of frequencies, which corresponds to different circumferential numbers, can change.

If we analyze the case of combined motion of reservoir on pendulum suspension with free surface liquid on the basis of the system of motion equations (1)-(3) (in this case we can state $\varepsilon=0$ and miss the equation (2)), we again get two new frequencies, which correspond to normal oscillations. Their distribution will be

$$
\omega_{\alpha}^{N} \leqslant \omega_{\alpha}^{p}<\omega_{a}^{p} \leqslant \omega_{a}^{N} .
$$

Since normal frequencies for other circumferential numbers $(m \neq 1)$ will not change in this case new internal resonances can take place and arrangement of normal frequencies, corresponding to different values of $m$ will be different for cases of combined motion of the system and for motion of the system when motion of the carrying body is given in advance.

Remark. it is worth noting that at first sight these results contradict with well-known theorem of analytical mechanics, which states that in the case when we remove constraint (provide potential of motion to carrying body) normal frequency of liquid should decrease. However this is not so. If we remove constraint $\varepsilon=0$ or $\alpha_{2}=0$ the system performs motion without external loading. In this case new constrains, which are equivalent to laws of conservation of linear (for $\alpha_{2}=0$ ) and angular $(\varepsilon=0)$ momentums, are superimposed on the system. It is interesting to note also that degree on restriction of motion of the constraint, connected with conservation of linear momentum is higher that in the case of immovable reservoir. This is confirmed that normal frequency of this motion is greater than partial frequency.

Let us confirm the above described results by numerical examples in the case of translational and rotational motion of the carrying body.

\section{Numerical example. Translational motion of the carrying body}

Let us consider the generalized Faraday problem. Similar to the classical Faraday problem reservoir performs vertical motion according to the given harmonic law $\varepsilon_{z}=H_{z} \cos (p t)$, but in contrast to the classical case reservoir has supplementary degree of freedom and can perform motion in the horizontal direction coupled with motion of a liquid free surface (Fig. 1). In contrast to previously studied problems we consider the case when due to combined character of motion the normal frequency corresponding to circumferential number $m=1$ corresponds with the frequency of mode, which correspond to the circumferential number $m=0$ (which is impossible for immovable reservoir). 
Let us consider circular cylindrical reservoir of radius $R=1 \mathrm{~m}$ vertical longitudinal axis. Reservoir is filled by liquid with filling depth $H=0.5 \tilde{m}$. For this reservoir partial frequency for the first antisymmetric mode $(m=1)$ is $\omega_{1}^{p}=3.6216 \mathrm{~Hz}$ and for the first axisymmetric mode $(m=1)$ it is $\omega_{0}^{p}=5.9995 \mathrm{~Hz}$. It was found that for $M_{r}=0.038 M_{1}$ the for combined motion system possesses internal resonance, i.e., $\omega_{1}^{N}=\omega_{0}^{N}$. For comparison we consider the case when $M_{r}=0.7 M_{1}$, in this case we have no internal resonance and $\omega_{1}^{N}=0.77 \omega_{0}^{N}$. Initial state of liquid is specified in the following way $a_{1}(0)=0.01 R$. Motion in vertical direction is performed with amplitude $H_{z}=0.01 R$, and frequency $p=2 \omega_{1}^{N}$. For comparison we show amplitudes of oscillation of liquid on tank walls for resonant (Fig. 2) and non-resonant (Fig. 3) cases.

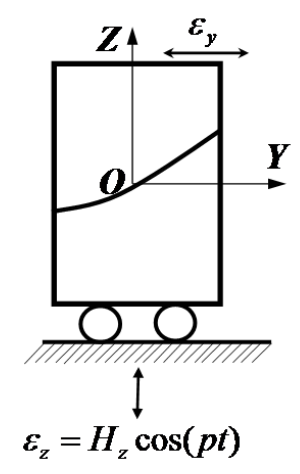

Fig. 1. Scheme of the generalized Faraday problem with potential of horizontal motion of the reservoir.

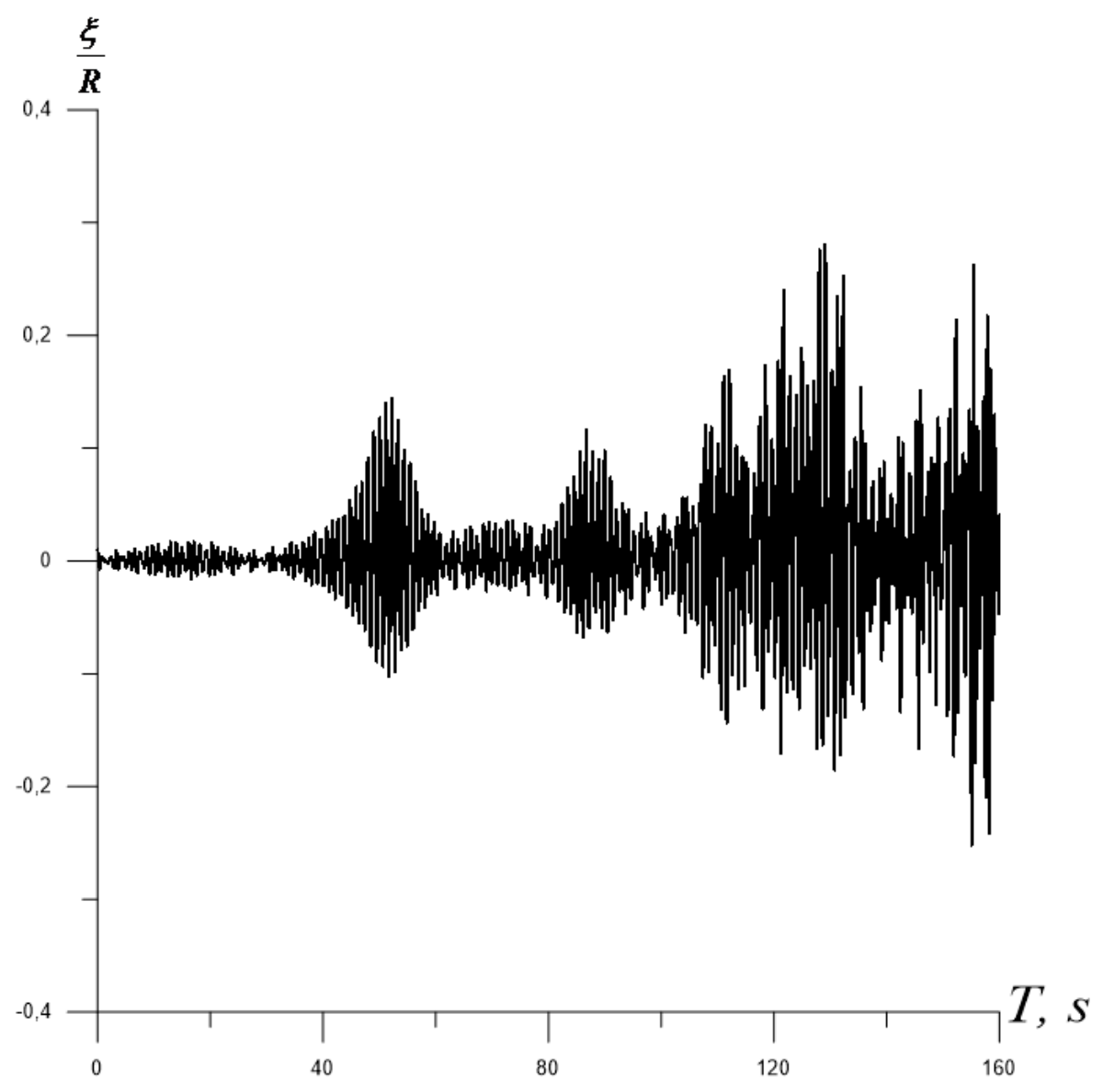

Fig. 2. Amplitudes on tank walls. Resonance.

As it is seen from Fig. 2 the presence of internal resonance results in considerable disturbance of high frequency modes. This is connected with essential contribution of the first axisymmetric normal mode, which defines intensity of energy exchange between normal modes in nonlinear range of excitation. In this case amplitude of the mode $m=1$ is excited considerably because of resonance effect. On the absence of internal resonance (Fig. 3) antisymmetric harmonic is mainly excited and amplitude of the mode for $m=0$ remains to be small. Therefore, considerable energy is focused mainly in the mode $m=1$, which promote greater amplitudes of perturbations on tank walls and because of small 


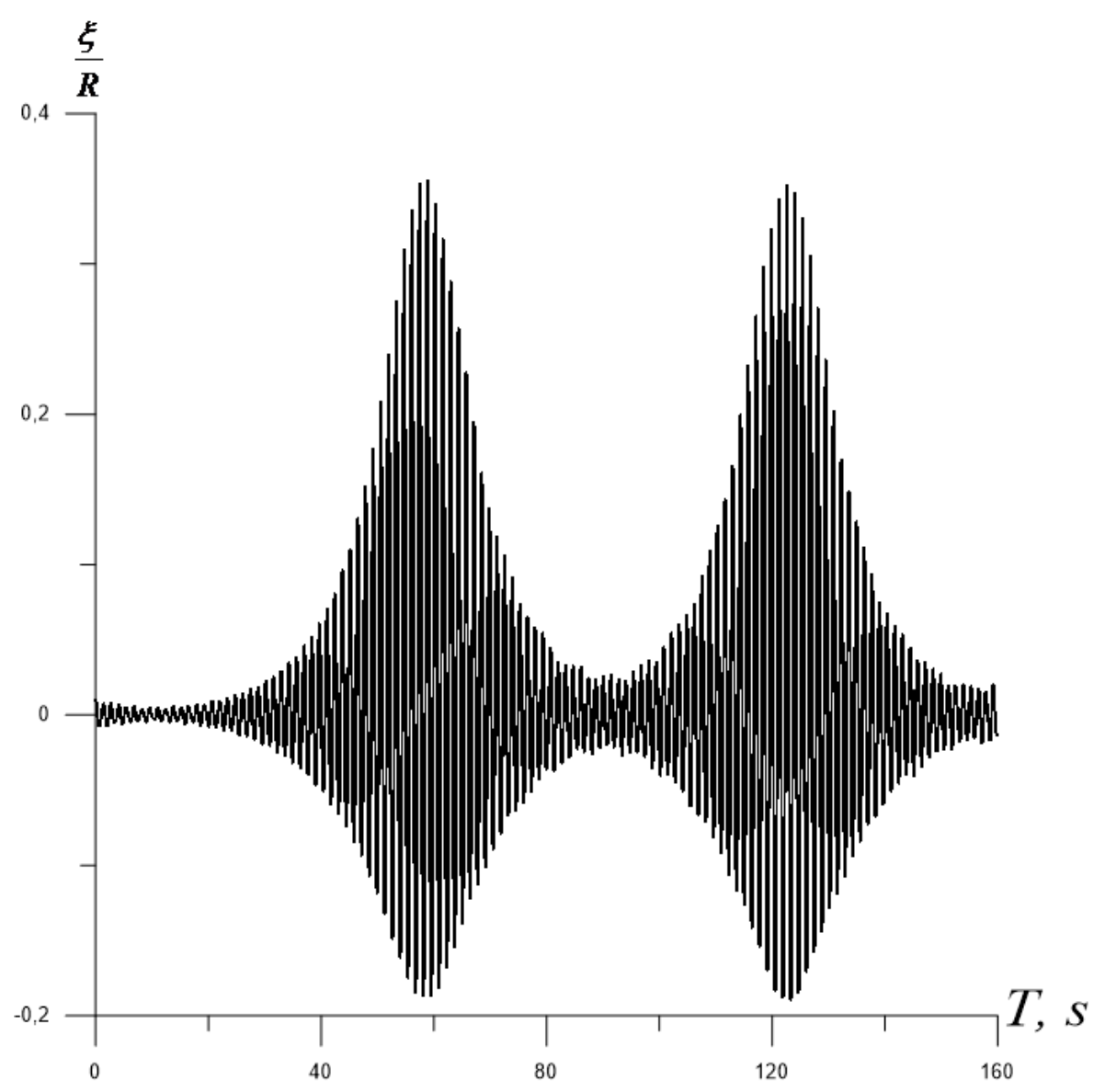

Fig. 3. Amplitudes on tank walls. No resonance.

perturbations of the mode $m=0$ amplitudes of high frequency modes are excited weakly in comparison with the case of resonance conditions.

Graphs Fig. 4 and 5 show peculiarities of horizontal motion of reservoir, which according to conservation of momentum occurs in antiphase to antisymmetric oscillations of liquid with a free surface. Under the absence of internal resonance effect of antiresonance is manifested (Fig. 5).

The described character of oscillations of liquid in reservoir is confirmed also by graphs of frequency spectrum of liquid free surface, shown in Fig. 6 and 7. On the absence of internal resonance (Fig. 7) main frequency dominates, however in the case of resonance process has multi-frequency character (Fig. 6), because simultaneously both parametric and forced mode of oscillations is manifested.

It is necessary to note that internal resonant for translational motion of the carrying body is manifested for great difference of masses of liquid and reservoir. So, practical significance of this effect cannot be frequently met.

\section{Numerical example. Rotational motion of the carrying body}

In contrast to translational motion of reservoir internal resonance in the case when carrying body performs rotational motion of pendulum suspension is occur for variation of parameters, which are frequently met in practice.

Let us consider the problem of dynamics of cylindrical reservoir with liquid on pendulum suspension under periodic harmonic loading. Initially the system is at rest state. Since suspension point is immovable, only reservoir performs only rotational motion. We consider the case when $M_{l}=0.25 M_{r}$. 


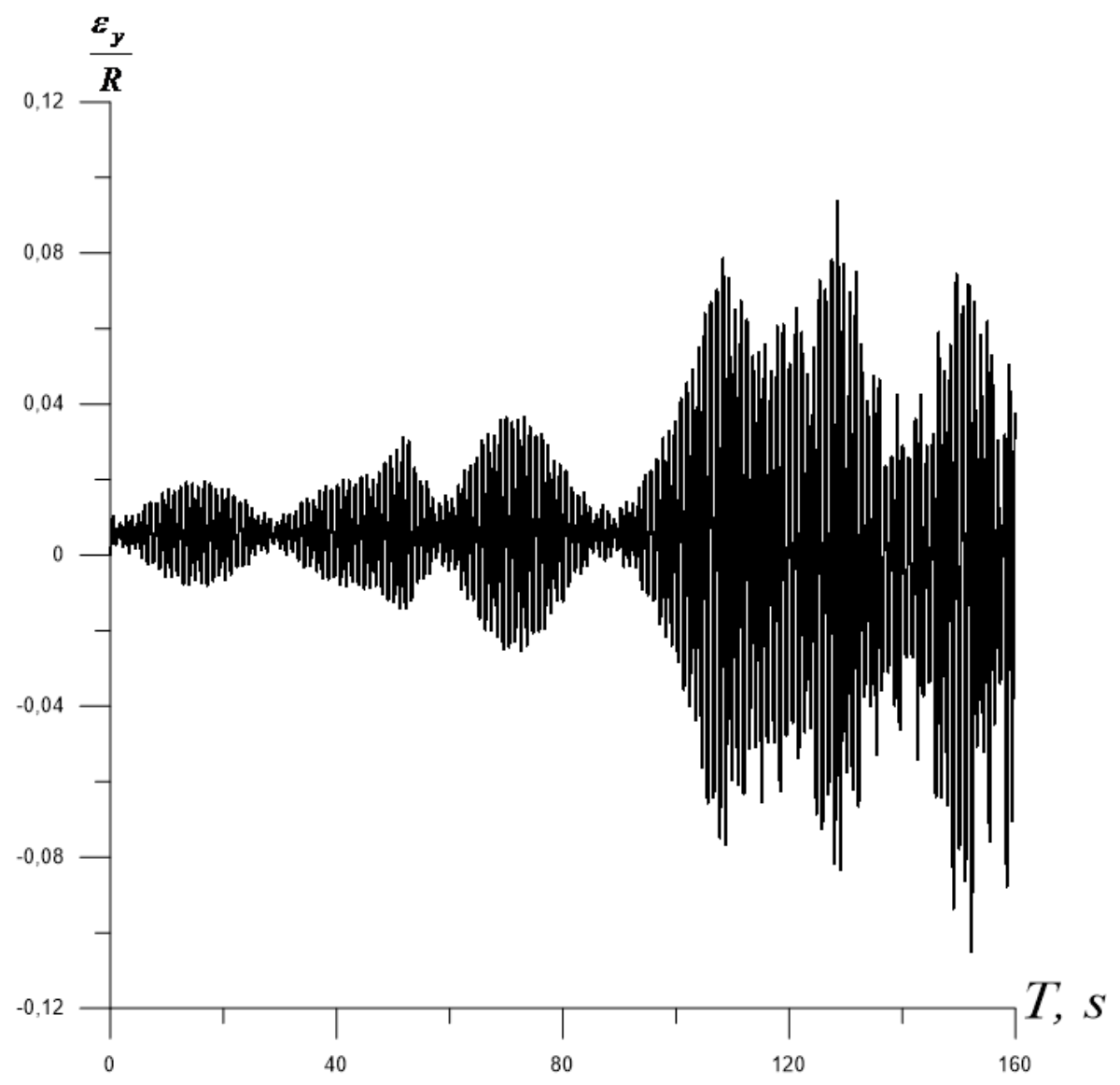

Fig. 4. Horizontal motion of reservoir. Resonance.

We supplemented the dynamical model by the generalized damping according to the approach [4]. The problem is solved in combined statement.

Initially let us study arrangement of partial and normal frequency in the case of system combined motion of reservoir with suspension length $l=R$ (Fig. 8).

We denote partial frequencies with upper index $*$, normal frequencies are given without upper index. Lower index 0 corresponds to oscillations of the system like physical pendulum, index 1 and 2 correspond to normal modes with circumferential number $m=1$ and $m=0$. As it is seen from this diagram normal frequencies considerably change in comparison with partial frequencies. Especially this change is great in the case for $m=1$. Otherwise for $m=0$ partial and normal frequencies coincide. Investigations showed that depending on suspension length normal frequency for circumferential number will change from its partial value, which corresponds to $l \rightarrow \infty$, to arbitrarily great value, which corresponds to $l \rightarrow l^{*}=-\frac{M_{r} h_{r}+M_{1} h_{1}}{M_{r}+M_{1}}$, where $l^{*}$ is position of the system mass center. On this increase $\omega_{1}$ can coincide with frequencies, which correspond to $m \neq 1$, which can be considered as sequence of internal resonances. For example for $l=3.08 R$ we get that $\omega_{1}=\omega_{2}$, so for the selected suspension length we have internal resonance of the first antisymmetric and axisymmetric normal modes. Let us analyze the case, shown in Fig. 8 for $l=R$. In this case normal oscillations with $m=1$ loss role of the first resonance and become the third resonant frequency (frequency for $m=2$ becomes now the lowest). It is evident to expect that resonance with the frequency of the first antisymmetric normal mode will manifest not so sharply as in the case of considerably great lengths of suspension or in the case of translational motion of the carrying body, 


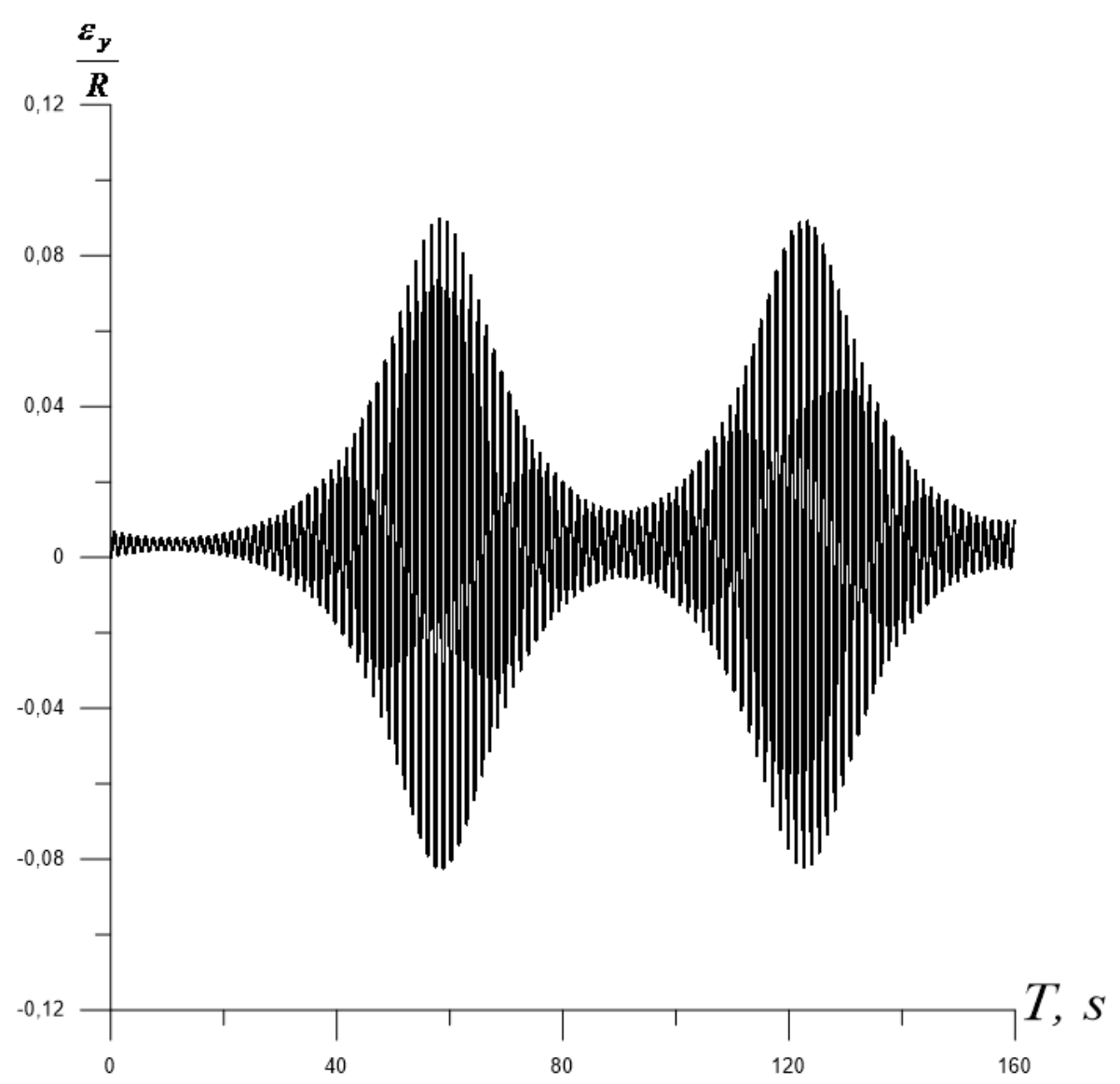

Fig. 5. Horizontal motion of reservoir. No resonance.

Numerical results showed that resonance for $\omega_{0}$ is manifested sharply, however the resonance for partial frequency $\omega_{1}^{*}$ is absent at all. For $\omega_{1}$ for $l=r$ is manifested weakly. because it is not the main resonant frequency.

Let us show development of dynamical processes for internal resonance $\omega_{1}=\omega_{2}(l=3.08 R)$. In this case we get the following variation of amplitude of xisymmetric (Fig. 9) normal modes in time.

To analyze the reason of rather specific slow development of resonance we perform spectrum analysis in the system, Fig. 10 corresponds to frequency close to resonance and Fig. 11 corresponds to resonance free domain.

As it is seen from figures in the case of internal resonance in contrast to resonance free mode of motion there are components of spectrum in aggregate interaction of axisymmetric mode with other component of the system, which are close to resonant frequency. Finally we can state that there is frequency excitation in resulting generalized force, which is created by nonlinear terms, therefore, resonance is developed. However its development is very slow because for axisymmetric mode of motion there is no means to cause its oscillations by either translational or rotational motion of carrying body.

\section{Conclusions}

We characterize differences in manifestation of dynamical properties between the cases of specified and combined motion of the carrying body with free surfaced liquid.

The main result of analysis of dynamical behavior of these systems make it possible to draw conclusion that in the case of combined motion of the system usual distribution of frequencies, peculiar to the case of immovable or movable according to the specified law carrying body, is violated considerable. If we arrange traditionally frequencies in ascending order, both magnitudes of frequencies 


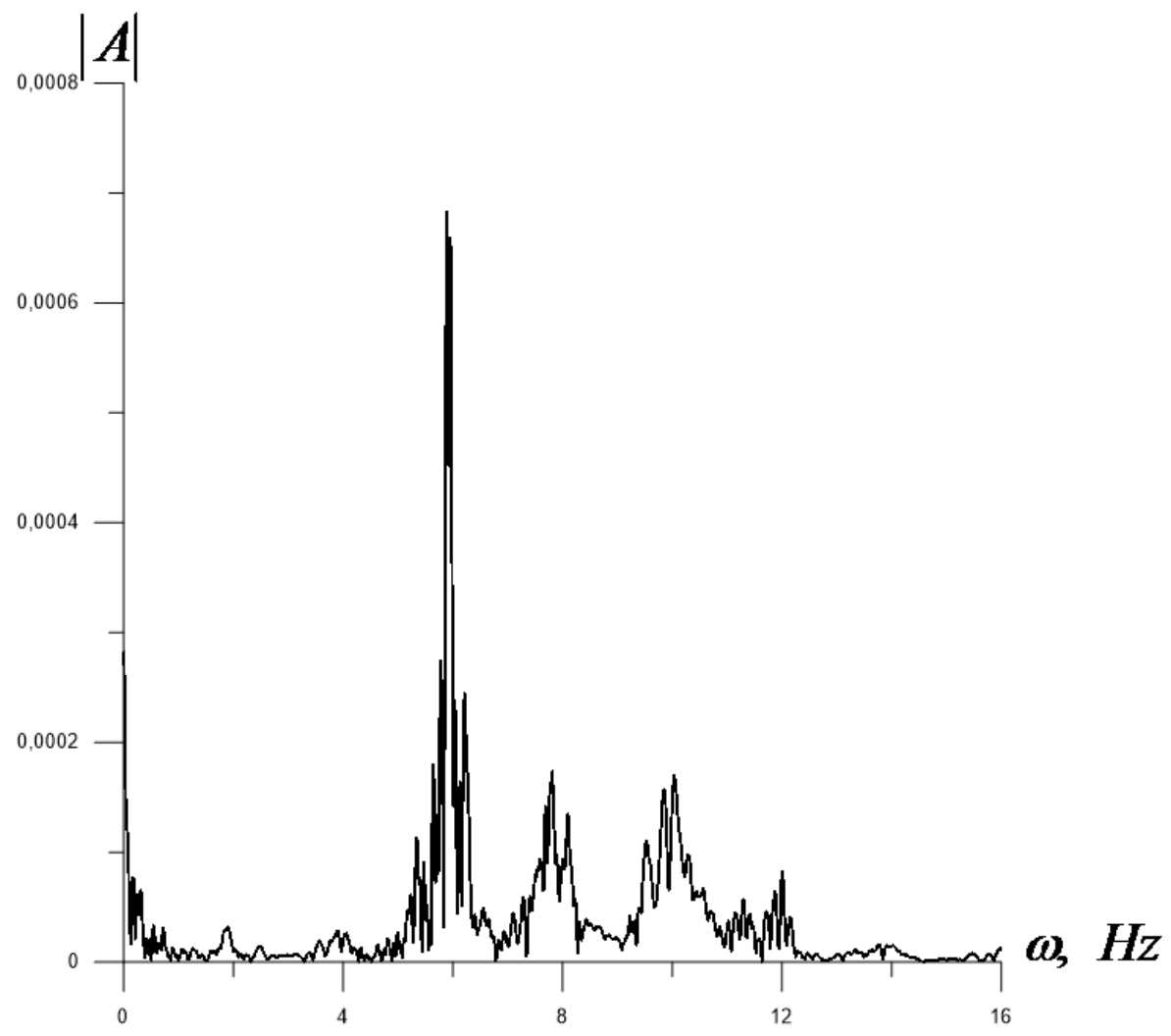

Fig. 6. Frequency spectrum. Resonance.

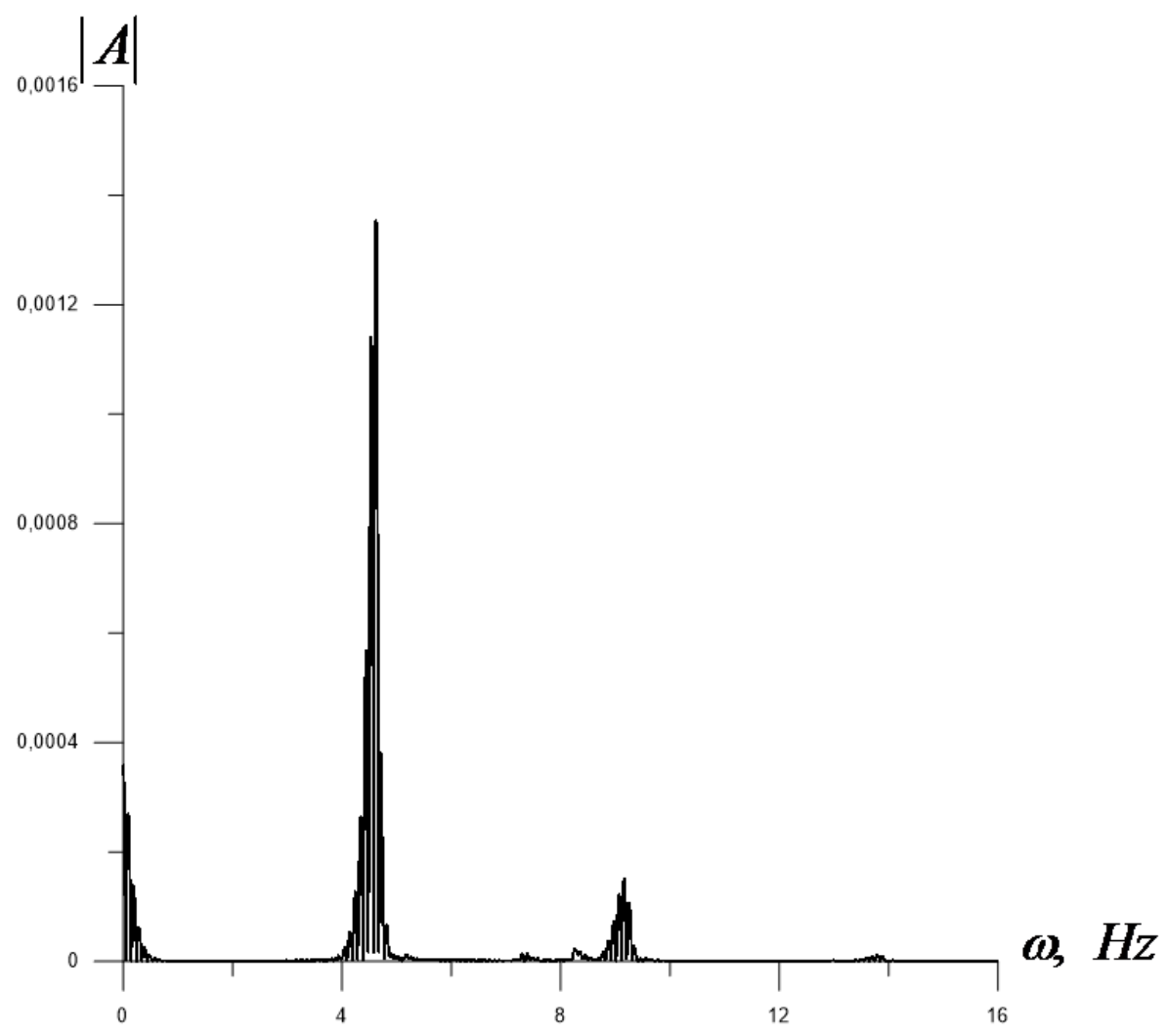

Fig. 7. Frequency spectrum. No resonance. 


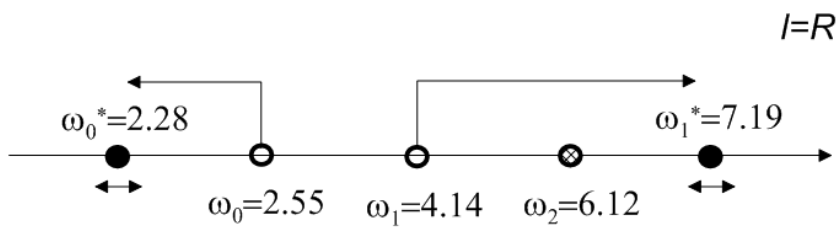

Fig. 8. Arrangement of partial and normal frequencies for angular motion of the carrying body.

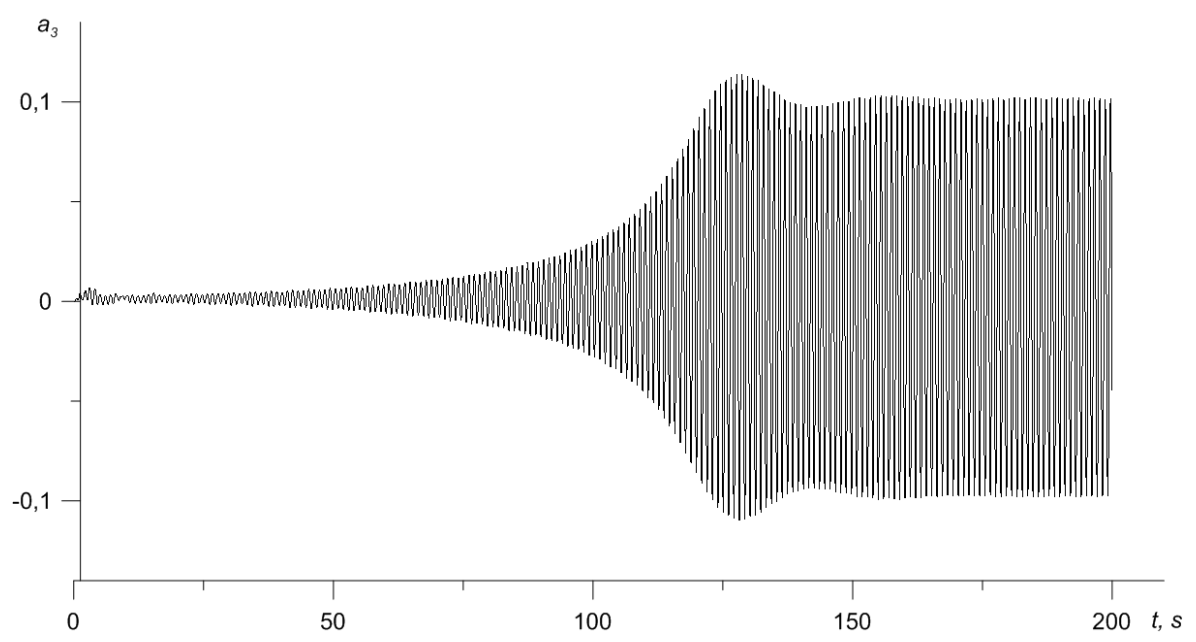

Fig. 9. Amplitude of the first axisymmetric normal mode.

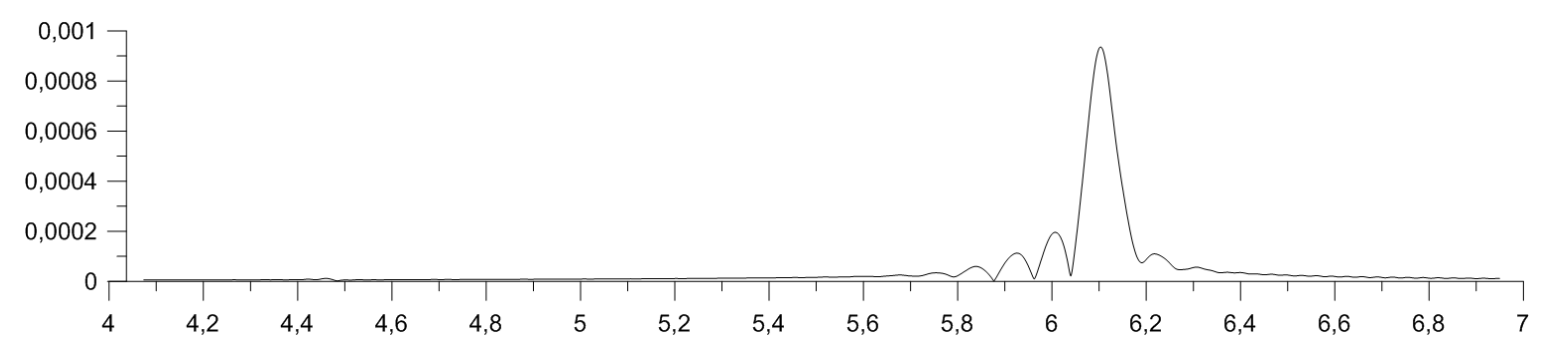

Fig. 10. Frequency spectrum in the case of internal resonance.

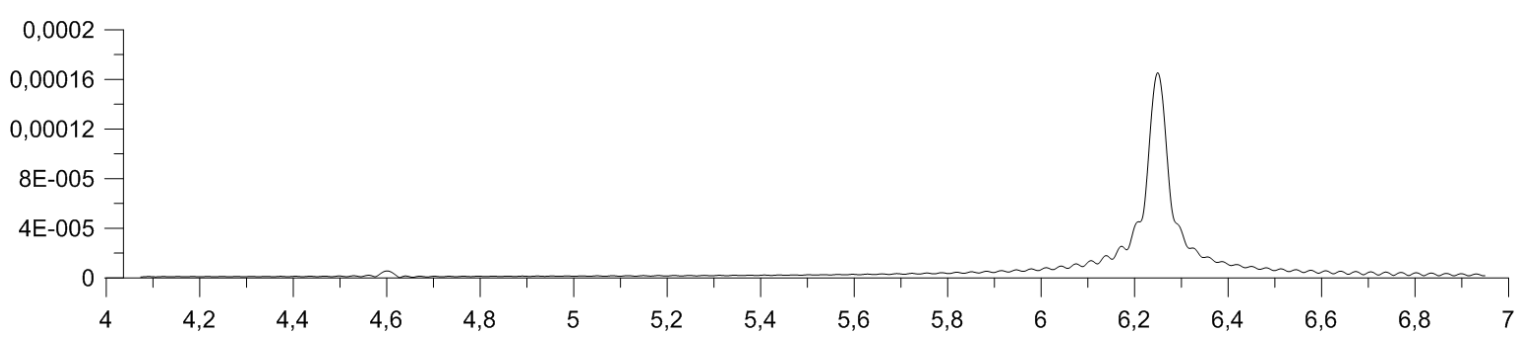

Fig. 11. Frequency spectrum in the case of absence of internal resonance.

and arrangement of modes of motion of a liquid free surface are different in the case of specified and combined motions. Frequencies of antisymmetric normal modes considerably depends on manner and parameters of reservoir fixing and for different ration of masses of liquid and carrying body can change in such that their changing can violate usual arrangement of frequencies and for some parameters internal resonances can happen. It was shown that changes of frequencies is in good agreement with theorems about changes of frequencies, known from analytical mechanics and theory of oscillations.

For confirmation of these ideas we consider two examples of combined motions of free surfaced liquid and carrying body, namely, the generalized Faraday problem about parametric resonance of 
oscillations of liquid free surface on oscillating in vertical direction of cylindrical reservoir, which motion in horizontal direction is not fixed, and angular motion of cylindrical reservoir on pendulum suspension with different lengths. For these system we showed peculiarity of development of internal resonance.

It was shown also that usual investigation of dynamics of liquid with a free surface in immovable or movable according to the given law carrying body is rather narrow and incomplete class of manifestation of nonlinear properties of fluid-structure interaction.

[1] Ibrahim R. A. Liquid sloshing dynamics: theory and applications. Cambridge University Press (2005).

[2] Limarchenko O. S., Yasinskiy V. V. Nonlinear dynamics of structures with liquid. National Technical University of Ukraine "KPI", Kiev (1997).

[3] Strelkov S. P. Introduction to theory of oscillations. Nauka, Moscow, (1964).

[4] Mikishev G. N., Rabinovich B. I. Dynamics of rigid bodies with cavities partially filled by liquid. Mashinostroenie, Moscow, (1968).

\title{
Вплив сумісності руху на зміну резонансних властивостей в задачі про коливання рідини з вільною поверхнею
}

\author{
Константінов О. В. ${ }^{1}$, Лимарченко О. С. ${ }^{2}$, Семенович К. О. ${ }^{3}$ \\ ${ }^{1}$ Інститут математики НАН Украӥни, вул. Терещенківсъка, 3, 01601, Киӥв, Украӥна \\ ${ }^{2}$ Київсъкий національний університет імені Тараса Шевченка \\ проспект академіка Глушкова, 4-Е, 01033, Київ, Україна \\ ${ }^{3}$ Київсъкий національний університет імені Тараса Шевченка \\ проспект академіка Глушкова, 4-Е, 01033, Київ, Україна
}

\begin{abstract}
Вивчається зміна резонансних властивостей системи рідина - конструкція, зумовлена зміною розподілу власних частот коливань. Показано, що різні типи рухомості тіла, що несе рідину, (поступальний або обертальний рух з різними в'язями) спричиняють збільшення величин власних частот, які відповідають антисиметричним коливанням вільної поверхні рідини, а інші частоти залишаються незмінними. Звичайний розподіл власних частот, який відповідає випадку нерухомого резервуару суттєво порушується. В цьому випадку проявляються деякі нові типи внутрішніх резонансів в системах рідина - конструкція. Були досліджені дві базові задачі з перерозподілом порядку власних частот: параметричний резонанс у рухомому в поперечному напрямку циліндричному резервуарі в узагальненій задачі Фарадея і в вимушених коливаннях рідини в циліндричному резервуарі на маятникову підвісі з різними довжинами підвісу. Обговорюються деякі загальні закономірності развитку динамічних процесів у цих системах.
\end{abstract}

Ключові слова: нелінійна динаміка рідини, коливання вільної поверхні, сумісний рух, перерозподіл власних частот

2000 MSC: 76B07, 76B99

УДК: 532.595

Mathematical Modeling and Computing, Vol.2, No. 1, pp. 48-57 (2015) 